\title{
GLOBALIZAÇÃO E TRABALHO: perspectiva comparativa entre Norte e Sul
}

\author{
INTRODUÇÃO
}

Pada Cappelin*

Chistian Azaiis*

Seguindo uma abordagem comparativa, este dossiêreúneartigos cujo objeto érefletir sobreas recentes transformações, em diversas sociedades contemporâneas quemanifestam aforça demecanismos de desregulamentação dos mercados de trabal ho edo emprego, assim como a desregulação dos regimes de solidariedade e proteção social. Vários países são colocados a confronto: Brasil, Cabo Verde, França, Portugal, Uruguai e, em menor medida, os Estados Unidos ea União Européia.

O fenômeno da global ização parece estar sufocando as perspectivas disciplinares, dificultando a compreensão da noção de espaços nacionais, subordinando a dimensão regional dosfenômenoseval orizando os acontecimentos internacionais. Os artigos apresentados neste dossiê têm em comuma idéia demanter ativa uma perspecti-

* Professor-Doutor do Departamento de Sociologia e do Programa de Pós-Graduação em Sociologia e Antropologia da Universidade Federal do Rio de Janeiro. Pesquisadora CNPq. Largo S. Francisco de Paula, n. 1 - Rio de Janeiro - RJ - Brasil. cappellin@uol.com.br

**Professor-Doutor da Universidade de Picardie Jules Verne (Amiens-França). Pesquisador no IRISES UMR 7170 Paris Dauphine. IRISES (UMR 7170 CNRS) Université Paris Dauphine - 75775 Paris Cedex 16. christian.azais@dauphine.fr va de territorialidade das manifestações, problematizando a atual ênfasequesubordinatoda e qual quer alteração das relações sociais à força reorganizadora dagl obal ização. Esta preocupação de situar nos espaços nacionais territorializados as recentes transformações queatingemas relações detrabal ho, as configurações do mercado detrabaIho, as práticas denegociação e de relaçõesindustriais, emais aindaas modalidades dedesregulação dos sistemas de inserção no trabalho, é fruto do interesses dos pesquisadores de identificar as especificidades desses países. Alguns desses artigos chegam a questionar sobre as diferentes formas de inserção dos indivíduos nestes espaços sociais, e, deoutro, mostram a amplitudedosimpactos da gl obal ização sobreas formas deinserção no mercado detrabal ho.

O que reúneos autores étambéma ousadia intelectual de buscar nas reflexões cruzadas Sul e Norteos processos quediferenciameaproximam as sociedades nacionais. Esteexercícioépossível pel o fato dos autores adotarem como central o conceito desociedadesal arial. Esteconceito, proposto por Castel (1995), tem um estatuto diferenciado 
da "relação salarial" fordista, própria à Escola da Regulação francesa. Elerefere-sea uma moldagem entre história eeconomia, ondea relação sal arial podeassumir configurações diferentes quando se localizam as transformações quecomandamas relações cada vez mais conflituosas na relação entre o público eo privado, quando se redefinem olugar do Estado neste processo.

A análise da regulação diferenciada dos mercados de trabal ho no Sul eno Norte podeser compreendida mediante o acompanhamento do grau de desmercantilização/remercantilização da forçadetrabal ho quecadaumadas sociedadesatingiu ao longo de seu desenvolvimento, ou ainda, da solidez/fragil idade/inexistência desuas sociedadessalariais.

O dossiêprocurou explorar esta problemá ticareunindo artigos deautores quecompõemuma equipedepesquisa, comformação multidisciplinar, na medida em que agrega um cientista político, economistas esociól ogos.

A ordem de apresentação dos artigos obedeceà seguintelógi ca: o primeiro texto, deOlivier Giraud, trata de forma teórica a questão da gl obal ização; o segundo texto, de Liana Carleial e Christian Azaïs aborda, de um ponto de vista macro, as transformações pelas quais os mercados detrabal ho da França edo Brasil, principalmente, estão passando; a partir do terceiro artigo entra-se numa análi ise centrada em diversos grupos sociais, os empresários com Paola Cappellin, os sindicatos com Francisco Pucci e os trabal hadores na pluma deCinara Rosenfield.

Olivier Giraud apresenta as várias facetas do conceito de gl obalização, lembrando que seo conceito não énovo, ele passou a ter feições múltiplas quenão selimitamà abordagem econômica. Para o autor, a gl obalização éantes de mais nada umfenômeno sociológico. A global ização éentão atransformação do quadro deinscrição do social. Os grupos, as identidades, as organizações, a ação coletiva, o poder, etc. são fenômenos sociais que não selimitam a uma inscrição num espaço social em tensão entre o local - como lugar deemergência- e o nacional como lugar de ressonância. Os diferentes fenômenos sociais abrangi dos existem, têmum significado, seconectam, têm conseqüências, seinterrelacionam num espaço mais amplo, num espaço gl obal. Na maioria dos setores mais difusos e menos estruturados do que os espaços nacionais, esteespaço gl obal toma profundidade, senutre, seconstrói incessantemente. No esporte, naarte, emvários setores industriais- automóvelou dos serviços - os softwares demanagement - e no setor da energia ou da ciência, esteespaço global édefato altamenteestruturado. Noâmbito desta leitura peculiar da gl obal ização, o artigo col oca a questão das definições e dos mecanismos precisosquecaracterizamaglobal ização. Eleindaga principal mentea universal idadedestefenômeno. Os mecanismosque "fazem" a gl obal ização seaplicam demaneira comparável nos países do Norteenos países do Sul? Como a gl obalização afeta a distância eas clivagens que separam os países do Norte edo Sul?

O segundo artigo, de autoria de Liana Carleial eChristian Azaïs assume como central as configurações dos mercados detrabal ho, debatendo o conceito de hibridização. Os países colocados frente a frente são a França, o Brasil e, em contraponto, os Estados Unidos. Duas idéias principais são aqui desenvolvidas. Primeiro, sedefendea asserção segundo a qual o movimento deuniformização constatado entreos mercados detrabaIho do Nortee do Sul émais aparente do que real, em razão de uma inscrição diferenciada dos países na globalização. Com isto, os autores sublinham o fato de quelongedaforma estatal ter desaparecido, ela éincontornável para apreender este processo. A mudança na natureza dos contratos de trabal ho, sua multiplicação, a permanência e até a consolidação do assalariamento, de forma opostaàs expectativas eaos preconceitos, constituem processos dos quais não escapam nem um país desenvolvido como a França, nem o Brasil, conhecido pela importância estrutural deseu "setor informal". O conceito de hibridização traduz as diversas formas deflexibilização eprecarização vivenciadas pel os trabal hadores do NorteedoSul; ele mostra que as semel hanças são aparentes. A 
segunda asserção trata da desregulamentação do mercado detrabal ho que, ao oposto dasidéias veiculadas pel os economistas liberais, defensores de umaflexibilização deummercado detrabal hotido como demasiado rígi do, éapresentada como condição sine qua non para al cançar o equilíbrio no mercado detrabal ho. No entanto, elas não são criadoras de empregos. Os exemplos dos Estados Unidos e, em menor medida, de países como a França eo Brasil confirmamtal proposição.

A ruptura entreemprego/proteção social e diferenciadas modalidades desolidariedadenacional são manifestações quetêm proporcionado a circulação internacional do lema da responsabilidadesocial, entendida como recurso retórico empresarial. Assumindo o interesse de diferenciar a aparente homogeneidade deste lema nos meios empresariais, as autoras Paola Cappellin eRaquel Giffoni Pinto tratam detrês percursos: EUA, Brasil eUnião Européia. No primeiro caso, éevidente que as pressões de diferentes atores sociais são dirigidas às empresas estado-unidenses, ao longo dos anos 1960. No Brasil, as el aborações do lema deresponsabilidadesocial provêm deassociações empresariais em meados dos anos 60 ese ampliam justo quando a sociedade, no fim dos anos 1990, demanda prosseguir em direção a integrar o compromisso da aplicação das normas e direitos do trabal ho. NaUnião Européia, estelema envolve o empresariado no final da década de 1990, com o compromisso de fazer retroagir a al ta taxa dedesemprego estrutural. Esta percepção comparativa internacional chega a demonstrar a variedade de conteúdos da responsabilidade social que busca dar conta da grandequestão hojeem debate nas sociedades: recompor o compromisso da ca pacidadedo vínculo deemprego ser fontedecida dania social.

Sucessi vamente a complexidade das relações entrenação, mercado detrabal hoeintegração regional é desenvol vida pelo artigo de Francisco Pucci. Tendo como referênciaa real idadenacional do Uruguai, o autor analiza a evolução das relações laborais no marco dos processos de reestruturação produtiva que começam a ser implementados a partir da conformação demercados regi onais no ConeSul. A hipótese defendida é que as transformações no mundo do trabalho, ocorridas no Uruguai, não dizem respeito unicamente à aplicação de um modelo econômico ou social específico de desenvolvimento, mas estão também inscritas em modificações estruturais de longo prazo, associadas às mudanças nas rel ações sociais quese produzem em escal a mundial. Contudo, a evolução concreta das relações laborais se explicamatravés das características específicas dos processos deintegração regional tal como vêm se conformando no âmbito do MERCOSUR.

Final mente, a perspectiva das mudanças no reconhecimento social dos sujeitos em práticas de trabal ho inseridos no setor de Tecnol ogias de Informação eComunicação (TICs) étratada pelo artigo de Cinara L. Rosenfield, quando oferece uma análisecomparativa entre Brasil, Portugal eCabo Verde. O objetivo da autora écompreender o contexto do trabal ho na chamada sociedade da informação eas diferentes formas detrabal ho quenela sedesenvolvem, em especial o tel etrabal ho em call centers. Diantedeum novo paradigmatecnológico característico daera dainformação, trata-sedeana lisar as novas maneiras detrabal har eas diferentes dimensões do trabal ho. A Teoria Crítica de Axel Honneth permiteàautora pensar a experiência do trabal ho no seio daquil o que o autor intitula "paradoxos do capitalismo". O significado do trabaIho em sua dimensão social ganha força ao ser demonstrado queo "novo capital ismo" logra produzir progresso moral, baseado nos legados do Estado Social edo modelo taylorista efordista de trabal ho, e, simultaneamente, produzir o seu contrário ao erodir o al canceemanci pador dessas normas e val ores. Os paradoxos do capital ismo em redeencontram no trabal ho emcall centers a produção exemplar desta contradição. 